\title{
Economic-Mathematical Methods of Forming the Optimal Assortment Plan Trade Enterprises
}

\author{
Shabanova L. B. ${ }^{1}$, Gafurov I. R. ${ }^{2}$, Safiullin N. Z. ${ }^{2} \&$ Salimov L. N. ${ }^{3}$ \\ ${ }^{1}$ Kazan Institute (branch), "Russian Economic University" named after G.V. Plekhanov, Kazan, Russia \\ ${ }^{2}$ Kazan Federal University, Institute of Management, Economics and Finance, Kazan, Russia \\ ${ }^{3}$ Institute of Economics, Management \& Law (Russia, Kazan), Kazan, Russia \\ Correspondence: Shabanova L. B., Kazan Institute (branch), "Russian Economic University" named after G.V. \\ Plekhanov, Kazan, 420111, Russia.
}

Received: March 10, 2015 Accepted: March 31, 2015 Online Published: April 30, 2015

doi:10.5539/ass.v11n11p142 URL: http://dx.doi.org/10.5539/ass.v11n11p142

\begin{abstract}
The article provides a critical analysis of the existing economic and mathematical models, summarizes the main deficiencies identified by various researchers and authors themselves, which allowed to recommend greater use of methods of linear programming. In a highly competitive consumer market, and most importantly, in the context of the dynamic expansion and deepening of product range, it is impossible to form the optimal assortment plans, focusing only on maximizing profits, it is also necessary to minimize distribution costs. According to the authors duality theory solves both of these problems. An algorithm for creating the optimal assortment plan commercial enterprise, based on the solution of the primal and dual linear programming problem. Given the economic interpretation of the possible reasons for which the task will not have a solution.

Existing computer technologies allow to realize the proposed algorithm and provide a high reliability of the results.
\end{abstract}

Keywords: economic and mathematical models, algorithms, methods of linear programming, duality theory, the assortment plan

\section{Introduction}

Currently, the ability to quickly assess the competitive position of the company and maintain a profitable financial and economic activity can only be based on the modern theory and advanced mathematical apparatus. However, it still remains urgently improve the reliability, reality and predictive accuracy of mathematical economic models.

With the growing competition in the consumer market, broadening and deepening product range (saturation as-commodity assortment of large commercial enterprises today tens of thousands of commodity products) can not be limited only solution of this problem in order to maximize profits. Duality theory allows us to find the optimal assortment plan at minimum cost circulation. It is advisable to use an algorithm of creating the optimal assortment plan, based on the solution of the primal and dual linear programming problem. Mastering this algorithm for solving the problem will not only maximize profits from sales, but also to minimize distribution costs.

Analysis of the most economic and mathematical models allow researchers to identify the different number of significant disadvantages to them:

Firstly, the basis for the construction of economic and mathematical models are the initial conditions and limitations, which are often not specific nature. Modelers sometimes specially selected raw numbers, so that models are not adequate to reality;

Second, none of the known models in comprehensiveness of factors is not perfect, as all actually existing conditions can not be covered;

Third, based on the development of many economic and mathematical models are hypotheses and axioms, thus, most of these models predict the conclusions that I want to get themselves insert handler; 
Fourth, most models of economic processes and phenomena are based on the most well-known model of supply and demand. However, in the graphs of supply and demand is not reflected the time factor, but to illustrate the processes used by the plane, which can be reflected only two factors. In reality, all these processes take place in three-dimensional space in which the intersection of supply and demand curves is only possible if a certain probability. In the plane (as part of the considered three-dimensional space) intersect only the projection of the real supply and demand curves, and these curves are not themselves.

Marketing analysis of enterprises in Russia, assessment of the role of consumer spending in ensuring the dynamics of the Russian economy, as well as study models the interaction of firms and components of the environment in Russia has a particular organization (Bagautdinova, Safiullin, \& Badrtdinov, 2014; Bagautdinova, Safiullin, \& Minnahmetov, 2014; Safiullin, Samigullin, \& Safiullin, 2013).

\section{Method}

The methods of linear programming and duality theory for the construction of economic and mathematical model to solve actual problems of commercial enterprises to build the optimal assortment plan. Under present conditions, these methods are widely used (Pang, Liu, \& Vanderbei, 2014; Mangasarian, 2014; Mansini, Ogryczak, \& Speranza, 2014; Sidhu, Kumar, \& Appadoo, 2014). From our point of view, in order to improve the reliability and practical significance of modern economic and mathematical models must make greater use of linear programming techniques.

Performance analysis of commercial enterprises showed that the region of its maximum efficiency is at the intersection of the two approaches to the formation of the retail price of the product. Modern marketing policy is that you must start with the establishment of end-user prices, then determine the share of the profits of all participants and their physical distribution costs. Financial policy, on the contrary, is that they begin with the calculation of distribution costs and add the desired profit for the retail price limit. Setting the price, marketing based on the fact that the amount of demand depends on the retail price. Reducing rates typically maximizes demand, and hence increase the mass of profits. But the extremely low price may not recover even distribution costs. Consequently, marketers and financiers in the formation of prices for goods have to find a compromise solution and form optimal assortment plan the sale of goods.

\section{Result}

The assortment plan should include products that provide maximum demand and maximum profit at minimum cost circulation. Form such optimal assortment plan can be achieved by solving the primal and dual problems of linear programming, mathematical models are presented below.

A mathematical model of the direct problem:

$$
\sum_{j=1}^{n} a_{i j} x_{j} \leq b_{i},(i=\overline{1, m})
$$

where $a_{i j}$ - costs $i$ residence $j$ товар;

$x_{j}$ - the number of each type of goods;

$b_{i}$ - the sum of the costs of circulation on articles or groups of costs.

$$
\begin{gathered}
x_{j} \geq 0, \quad(j=\overline{1, n}) \\
Z(X)=\sum_{j=1}^{n} c_{j} x_{j} \rightarrow \max ,
\end{gathered}
$$

where $c_{j}-$ profits from the sale of units of goods $j$ species.

A mathematical model of the dual problem:

$y_{i}-$ number of cost $i$ species.

$$
\sum_{i=1}^{m} a_{i j} y_{i} \geq c_{j}, \quad(j=\overline{1, n)},
$$

$$
y_{i} \geq 0, \quad(i=\overline{1, m})
$$




$$
F(Y)=\sum_{i=1}^{m} b_{i} y_{i} \rightarrow \text { min. }
$$

Suppose that financiers are predefined conditional permanent and semi-variable costs per unit of each type of product and the forecast amount of distribution costs for the whole company, which can not exceed. Suppose that it is necessary to form an assortment plan of several kinds of goods: $A, B, C$, that would ensure maximum profit commercial enterprise. It was found that the implementation of product $A$ requires semi-variable costs of circulation of 4.0 million. rubles per unit of goods and semi-fixed costs $-2.0 \mathrm{mln}$. rubles. Sale of goods $B$ requires a correspondingly - $2 \mathrm{mln}$. rubles and $6 \mathrm{mln}$. rubles. Sale of goods $C$ requires a correspondingly $6 \mathrm{mln}$. rubles and $4 \mathrm{mln}$. rubles. And the semi-variable costs of the company should not exceed $60 \mathrm{mln}$. rubles and conditional permanent - $45 \mathrm{mln}$. rubles. Planned profits from commodity unit $A$ is $12 \mathrm{mln}$. rubles, from commodity unit $B-15$ million. rubles, from commodity unit $C-19 \mathrm{mln}$. rubles. Aggregate the data in Table 1 .

Table 1. Initial data for the construction of the assortment plan, ensuring maximum profit

\begin{tabular}{ccccc}
\hline \multirow{2}{*}{ Costs } & \multicolumn{2}{c}{ Costs per unit of product, mln. roubles. } & \multirow{2}{*}{ The amount of costs, mln. roubles. } \\
\cline { 2 - 4 } & $A$ & $B$ & $C$ & 60 \\
Semi-variable costs & 4 & 2 & 6 & 45 \\
Fixed costs & 2 & 6 & 4 & 60 \\
\hline
\end{tabular}

It is necessary to find such an assortment plan in which distribution costs are not exceeded, and the profit will be maximized.

We give a mathematical formulation of the problem. Let $X=\left(x_{1}, x_{2}, x_{2}\right)$ - assortment plan product sales, where $x_{1}$ - number of items $A, x_{2}$ - number of items $B, x_{2}$ - number of items $C$.

Obviously, $x_{1}>=0 ; x_{2}>=0 ; x_{3}>=0$. If we consider that the costs of treatment should not be exceeded, then we obtain the following inequality:

$$
4 x_{1}+2 x_{2}+6 x_{3}<=60 .
$$

$2 x_{1}+6 x_{2}+4 x_{3}<=45$ Total profit depends on the number of each type of goods, and is a function of the unknown $x_{1}, x_{2}, x_{3}$, that is

$$
f(x)=12 x_{1}+15 x_{2}+19 x_{3} .
$$

Consequently, the problem reduces to finding a non-negative solution of a system of linear inequalities, which corresponds to the largest value of the linear function.

The mathematical model of the problem is as follows:

maximize $f(x)=12 x_{1}+15 x_{2}+19 x_{3}$

given that:

$$
\begin{gathered}
x_{1}>=0, x_{2}>=0, x_{3}>=0, \\
4 x_{1}+2 x_{2}+6 x_{3}<=60, \\
2 x_{1}+6 x_{2} \times 4 x_{3}<=45 .
\end{gathered}
$$

As noted above, financiers and marketing approaches to the formation of the assortment plan diverge. Unlike financiers marketers seek to include in the plan a product that will provide the maximum demand, usually by

\begin{tabular}{|c|c|c|c|}
\hline \multirow{2}{*}{ Goods } & \multicolumn{2}{|c|}{ Distribution costs per unit of product, mln.rub } & \multirow{2}{*}{ Profits mln.rub } \\
\hline & Semi-variable costs & Fixed costs & \\
\hline$A$ & 4 & 2 & 12 \\
\hline$B$ & 2 & 6 & 15 \\
\hline$C$ & 6 & 4 & 19 \\
\hline The sum of the costs of the entire plan & 60 & 45 & \\
\hline
\end{tabular}
lowering the price of the product. Achieve this without loss of profit is only possible by minimizing distribution costs.

Therefore, it is necessary to construct the dual problem to minimize distribution costs. The above transform the original data in the Table 2 .

Table 2. Initial data for the construction of the assortment plan, provides minimal distribution costs 
A mathematical model of the dual problem takes the following form:

minimize $G(y)=60 y_{1}+45 y_{2}$

in terms of: $y_{1}>=0, y_{2}>=0$,

$$
\begin{aligned}
& 4 y_{1}+2 y_{2}>=12, \\
& 2 y_{1}+6 y_{2}>=15, \\
& 6 y_{1}+4 y_{2}>=19,
\end{aligned}
$$

where $y 1$ and $y 2$ - respectively semi-variable and semi-permanent treatment of delay per unit of goods.

Solution algorithm. Direct linear programming problem to the canonical form and solved by the simplex method. In general, if the canonical form can not get permission (simplex) form, the linear programming problem has no solution in mind the incompatibility of restrictions. The mathematical model of the problem takes the following form:

$$
\begin{gathered}
2 x_{1}+x_{2}+3 x_{3}+x_{4} \ldots=30, \\
2 x_{1}+6 x_{2}+4 x_{3} \ldots+x_{5}=45, \\
x_{i}>=0, \text { где } i=1-5, \\
z=12 x_{1}+15 x_{2}+19 x_{3}+0 x_{4}+0 x_{5}-\max , \\
z-12 x_{1}-15 x_{2}-19 x_{3}-0 x_{4}-0 x_{5}=0 .
\end{gathered}
$$

\begin{tabular}{|c|c|c|c|c|c|c|c|c|c|}
\hline \multirow{4}{*}{0 step } & $\mathrm{Cb}$ & $\mathrm{B}$ & 0 & 12 & 15 & 19 & 0 & 0 & \multirow{2}{*}{ simplex relationship } \\
\hline & & & $P 0$ & $P 1$ & $P 2$ & $P 3$ & $P 4$ & $P 5$ & \\
\hline & 0 & $P 4$ & 60 & 4 & 2 & 6 & 1 & 0 & $60: 6=10$ \\
\hline & 0 & $P 5$ & 45 & 2 & 6 & 4 & 0 & 1 & $45: 4=111 / 4$ \\
\hline \multirow{4}{*}{1 step } & \multicolumn{2}{|c|}{$\overline{z_{j}-c_{j}}$} & 0 & -12 & -15 & -19 & 0 & 0 & \\
\hline & 19 & $P 3$ & 10 & $2 / 3$ & $1 / 3$ & 1 & $1 / 6$ & 0 & $10: 1 / 3=30$ \\
\hline & 0 & $P 5$ & 5 & $-2 / 3$ & $14 / 3$ & 0 & $-2 / 3$ & 1 & $5: 14 / 3=15 / 14$ \\
\hline & \multicolumn{2}{|c|}{$z_{j}-c_{j}$} & 190 & $2 / 3$ & $-26 / 3$ & 0 & $19 / 3$ & 0 & \\
\hline \multirow{3}{*}{2 step } & 19 & $P 3$ & $135 / 14$ & $5 / 7$ & 0 & 1 & $3 / 14$ & $-1 / 14$ & $135 / 14: 5 / 7=27 / 2$ \\
\hline & 15 & $P 2$ & $15 / 14$ & $-1 / 7$ & 1 & 0 & $-1 / 7$ & $3 / 14$ & \\
\hline & \multicolumn{2}{|c|}{$z_{j}-c_{j}$} & $2790 / 14$ & $-4 / 7$ & 0 & 0 & $27 / 14$ & $26 / 14$ & \\
\hline \multirow{3}{*}{3 step } & 12 & $P 1$ & $27 / 2$ & 1 & & & & & \\
\hline & 15 & $P 2$ & 3 & 0 & & & & & \\
\hline & \multicolumn{2}{|c|}{$z_{j}-c_{j}$} & 207 & 0 & 0 & $4 / 5$ & $147 / 70$ & $126 / 70$ & \\
\hline
\end{tabular}

The coefficients of the unknowns of the system limitations, the free terms, the coefficients of the unknowns of the objective function are recorded in Table 3.

Table 3. The algorithm for finding the optimal support program for solving the problem

Table $3 \mathrm{Cb}$ - coefficients of the basic variables;

$\mathrm{B}$ - basis;

$P_{0}-P_{5}-$ column vectors.

For each column vector calculated difference $Z j-C j$, where $C j$ - the coefficients of the objective function at baseline unknown.

View the values of the differences $Z j-C j$. If there is a difference $<0$ (the problem at max.), The plan is not optimal linear programming problem and must go to another support program.

Allowing selected column (vector introduced into the basis) at the lower negative difference $Z j$ - $C j$. Determined by the resolution of the string (vector injected into the base), which corresponds to the minimum quotient of the positive elements of the column of free terms to the corresponding positive elements allowing the column 
(simplex relations). If admissible simplex relations not, then the problem has no solution, because of the objective function is unbounded. In our case, the problem has a solution. The transition to the next step.

In our case, the problem has a solution. The transition to the next step. In Table 3, find the optimal support program, that is the solution of the direct problem of linear programming, thus building up the assortment plan, which brings the maximum profit.

$$
\begin{gathered}
Z_{\max }-12 \times 27 / 2+15 \times 3=207 \text { mln. rub } \\
x_{1}=27 / 2, \quad x_{2}=3, \quad x_{3}=0 .
\end{gathered}
$$

According to Theorem 1 , the duality theory objective function value maximization problem for any of its plan does not exceed the value of the objective function of the dual problem of minimizing its plan for any. In accordance with Theorem 2 of the same theory of optimal plan of the direct problem corresponds to the optimal plan its dual objectives, ie:

$$
\begin{aligned}
& y_{1}=21 / 10=2,1 \mathrm{mln} . \text { rub. } \\
& y_{2}=18 / 10=1,8 \mathrm{mln} . \text { rub. }
\end{aligned}
$$

Therefore, the solution of the direct and dual problems simplex method and using duality theory gives the following results. The maximum profit and minimum cost circulation amounted to 207 million rubles provided that the optimal assortment plan will be completed as follows: A product of $27 / 2=13.5$ units and goods in the amount of 3 units. Products $C$ with the best $B$ in the plan should not be included.

Duality theory allows us to estimate the size of distribution costs. Evaluation of semi-variable costs amount to 2.1 million rubles and semi-fixed - 1.8 million rubles per unit of product.

\section{Conclusion}

Modern computer technology allows fast enough to solve the problem by the proposed algorithm generate the optimal plan with a broad and deep product portfolio.

In case we are considering the problem has an optimal solution, we found the parameters under which will be formed optimal assortment plan. But the problem may not be the best plan. This situation arises in two cases.

In the first case, we propose a fundamentally new goods with higher costs, the customer needs. But they still do not have sufficient income to repay the retail price. In this case, the development and production of goods to be postponed until not found cheaper production technology, consumer income, or until they reach a sufficient level.

In the second case is made vital goods everyday demand, without which it is impossible the normal development of society. However, the cost of its production and sales are not compensated by the retail price. In this case it is necessary to find sources of subsidies for the production and sale of goods. For example, in many countries, including in Russia, production and sale of subsidized bread, services and passenger transport and other goods and services.

Consequently, the results of solving the problem of creating the optimal assortment plan with the help of the mathematical model proposed in each case must be subjected to a through economic and logical analysis.

\section{References}

Bagautdinova, N. G., Safiullin, L. N., \& Badrtdinov, N. N. (2014). The Role of Consumer Expenses in Ensuring Forward Dynamics of the Russian Economy. Mediterranean Journal of Social Sciences, 5(12), 43-48. http://dx.doi.org/10.5901/mjss.2014.v5n12p43

Bagautdinova, N. G., Safiullin, L. N., \& Minnahmetov, R. R. (2014). Institutionalization of Firm Environment in Conditions of Growing Turbulence. Mediterranean Journal of Social Sciences, 5(12), 55-58. http://dx.doi.org/10.5901/mjss.2014.v5n12p55

Demchenko, S. G., Faizkhanova, A. L., \& Fathiev, A. M. Private medical institutions gain over municipal ones in the competition for customers. Mediterranean Journal of Social Sciences, 5(18 SPEC. ISSUE), 263-268.

Fatkhiev, A. M., Safiullin, L. N., \& Safiullina, L. M. (2014). Projected trends and problems of education. Life Science Journal, 11(6s), 384-387.

Kadochnikova, E. I., \& Ismigilov, I. I. (2014). sssMeasurement of cognitive growth factors of regional economy based on panel data. Mediterranean Journal of Social Sciences, 5(24), 377-382.

Mangasarian, O. L. (2014). Absolute Value Equation Solution via Linear Programming. Journal of Optimization 
Theory and Applications. Springer. http://dx.doi.org/10.1007/s10957-013-0461-y

Mansini, R., Ogryczak, W., \& Speranza, M. G. (2014). Twenty years of linear programming based portfolio optimization. European Journal of Operational Research, 234, 518-535. http://dx.doi.org/10.1016/j.ejor.2013.08.035

Ovcharov, A. O., Fathiev, A. M. Statistical analysis of tourist food supply industry. Mediterranean Journal of Social Sciences, 5(18 SPEC. ISSUE), 269-274.

Pang, H., Liu, H., \& Vanderbei, R. (2014). The fastclime Package for Linear Programming and Large-Scale Precision Matrix Estimation in R. Journal of Machine Learning Research, 15, 489-493.

Safiullin, M. R., Samigullin, I. G., \& Safiullin, L. N. (2013). Model of Management of Competitiveness of a Machine-building Complex. World Applied Sciences Journal, 27(Economics, Management and Finance), 212-216.

Sidhu, S. K., Kumar, A., \& Appadoo, S. S. (2014). Mehar Methods for Fuzzy Optimal Solution and Sensitivity Analysis of Fuzzy Linear Programming with Symmetric Trapezoidal Fuzzy Numbers. Mathematical Problems in Engineering Volume. http://dx.doi.org/10.1155/2014/697085

\section{Copyrights}

Copyright for this article is retained by the author(s), with first publication rights granted to the journal.

This is an open-access article distributed under the terms and conditions of the Creative Commons Attribution license (http://creativecommons.org/licenses/by/3.0/). 